\title{
ECCENTRIC ODONTOGENIC MASS- A CASE REPORT
}

\author{
Saravana Selvam S1, C. S. C. Satish Kumar², Sathiya Jeeva³ M. A. Eswaran 4 , V. L.Vishanth ${ }^{5}$
}

${ }^{1}$ Senior Lecturer, Department of Oral Medicine and Radiology, Thai Moogambigai Dental College and Hospital, Chennai, T. N, India. ${ }^{2}$ Senior Lecturer, Department of Oral and Maxillofacial Surgery, Thai Moogambigai Dental College and Hospital, Chennai, T. N, India. ${ }^{3}$ Reader, Department of Oral Pathology, Thai Moogambigai Dental College and Hospital, Chennai, T. N, India. ${ }^{4}$ Reader, Department of Prosthodontics, Thai Moogambigai Dental College and Hospital, Chennai, T. N, India. ${ }^{5}$ CRI, Thai Moogambigai Dental College and Hospital, Chennai, T. N, India.

HOW TO CITE THIS ARTICLE: Selvam SS, Kumar CSCS, Jeeva S. Eccentric odontogenic mass- a case report. J. Evolution Med. Dent. Sci. 2018;7(34):3808-3810, DOI: 10.14260/jemds/2018/854

\section{PRESENTATION OF CASE}

A 45-year-old female patient came to our OP with chief complaint of pain in left lower back tooth region for past 6 months. Patient was apparently normal before 6 months, then she developed pain in relation to left lower mandibular region which was dull, intermittent and aggravated on mastication. There was no significant medical or family history.

After routine clinical examination, radiographic investigation was planned and explained to patient. Initially IOPA was taken, which revealed well-defined radiopaque mass structure. Then, to know about the exact location and the size of the mass structure, OPG was taken which again revealed well-defined radiopaque structure measuring approximately about $1.5 \times 1.5 \mathrm{~cm}$ in dimension.

Because of pain in that region, biopsy was planned under local anaesthesia and informed consent was obtained from the patient. Then, the mass structure was removed, and the specimen was sent to histopathological examination, which revealed the presence of enamel dentin pulp and cementum suggestive of a complex odontoma.

An eccentric odontoma is a hamartomatous lesion or malformation of odontogenic origin, in which both epithelial and mesenchymal cells reveal complete differentiation and all the dental tissues are represented. Though all structures may be present, it will be mostly in a disorderly model not resembling a tooth. ${ }^{1}$ The term "odontoma" was coined by Paul Broca in 1867. Broca defined the term as tumours formed by the overgrowth of dental tissue. ${ }^{2}$

World Health Organisation (WHO) classified it based upon their gross and radiographic features into compound (small tooth like structures) or complex (a conglomeration of dentin, enamel and cementum). ${ }^{3}$ A deformity in which all dental tissues are formed, but taking place in less orderly pattern is complex odontoma. A deformity in which all dental tissues are arranged in a more orderly pattern is compound odontoma. ${ }^{4}$

'Financial or Other Competing Interest': None.

Submission 07-07-2018, Peer Review 02-08-2018,

Acceptance 09-08-2018, Published 20-08-2018.

Corresponding Author:

Dr. Saravana Selvam $S$,

Senior Lecturer,

Department of Oral Medicine and Radiology,

Thai Moogambigai Dental College and Hospital,

Chennai, Tamilnadu, India.

E-mail: drsaravana2512@gmail.com

DOI: $10.14260 /$ jemds $/ 2018 / 854$
The majority of odontomas which are situated in the anterior region of the maxilla are compound, while the great majority of odontomas located in the posterior areas, especially in the mandible are complex odontomas. ${ }^{5}$

Odontomas may be found at any age; however, most are detected in the first two decades of life. There is no gender predilection and most lesions are detected on routine radiographs. Clinical symptoms are more uncommon. ${ }^{6}$ Here we present a remarkable symptomatic case of complex odontoma, which was radiographically similar to a compound odontoma.

\section{DISCUSSION OF MANAGEMENT}

Although, the aetiology of complex odontomas is not clearly known, several theories have been proposed which include trauma, infection, family history and genetic mutation. Such odontomas may be discovered at any age, but the age with the greatest prevalence is the second decade of life. ${ }^{7}$ These tumours have a slight male predilection and are commonly seen in the posterior mandible. ${ }^{8,9}$ Complex odontomas are mostly asymptomatic in nature and are usually found on routine radiographic examinations. ${ }^{2}$ But in our case, it was symptomatic.

The aetiology of complex odontomas is not clearly understood. However, several researchers have reported various aetiological factors including local trauma, infection, family history and genetic mutation. They have also suggested that complex odontomas are inherited from a mutant gene or interference, possibly postnatal with the genetic control of tooth development. 10

In majority of kids, these tumours are associated with tooth eruption disturbances such as delayed eruption of the deciduous and permanent teeth or overly retained deciduous teeth. $49 \%$ percent of odontomas were diagnosed as a result of delayed eruption, $28 \%$ with the retention of primary teeth, $20 \%$ were incidentally found on radiographs and $3 \%$ with the swelling of jaws. ${ }^{11}$

The radiological appearance of complex odontomas depends on their development stage and degree of mineralisation. The first stage is characterised by radiolucency due to a lack of calcification. Partial calcification is observed in the intermediate stage, while in the third stage the lesion usually appears radiopaque with amorphous masses of the dental hard tissue surrounded by a thin radiolucent zone corresponding to the connective capsule histologically. ${ }^{12}$

Histologically, the odontoma is not a diagnostic dilemma. It is composed of dentin, cementum, pulpal tissue and enamel. However, mature enamel is lost during the decalcification processing and will not be seen on conventional haematoxylin and eosin stained slides. The compound odontoma recapitulates the organisation of a 
normal tooth, but have less calcified pulp, primary dentine and enamel than the normal primary dental cement structure and as bone trabeculae between the denticles. The complex odontoma appears as a disorganised mass of hard odontogenic tissues and are characterised by primary dentine, normal or less calcified enamel, immature cementum and a capsule. ${ }^{13,14}$

It can be thought of an unknown agglomerated mass like structure. The mechanism of agglomerated mass eruption appears to be different from tooth eruption, because of lack of periodontal ligament and root. Although, there is no root formation in agglomerated mass, its increasing size may lead to the sequestration of overlying bone and hence results in occlusal movement or eruption. ${ }^{7}$ In our case all the structures of the teeth were present, which ruled out the possible diagnosis of agglomerated mass.

\section{FINAL DIAGNOSIS}

Hamartomatous formation frequently occurs in the jaw bones. They rarely erupt in the oral cavity and are mostly associated with an impacted tooth. The reported case is an unusual presentation of a complex odontoma, which occurred in left lower mandibular region mimicking a compound odontoma. Any well-defined tooth like radiopacity occurring in the mandibular region will be diagnosed as impacted tooth or other possible diagnosis of Compound/Complex Odontoma. Histopathological diagnosis is the Gold Standard in arriving at an ideal diagnosis, in our case it was exactly the same where radiographically considered compound odontoma was diagnosed as complex odontoma. Hence, histopathological diagnosis is The Diagnostic King in our field.

As we all know histological diagnosis is the gold standard, but by providing multiple differential diagnoses to a pathologist it makes him to arrive at an accurate diagnosis easily, where misdiagnosis will be out of the question. To provide multiple differential diagnoses, better understanding and current updates in subject is necessary. As health care professionals, we need to arrive at an accurate diagnosis within short duration for early treatment planning.

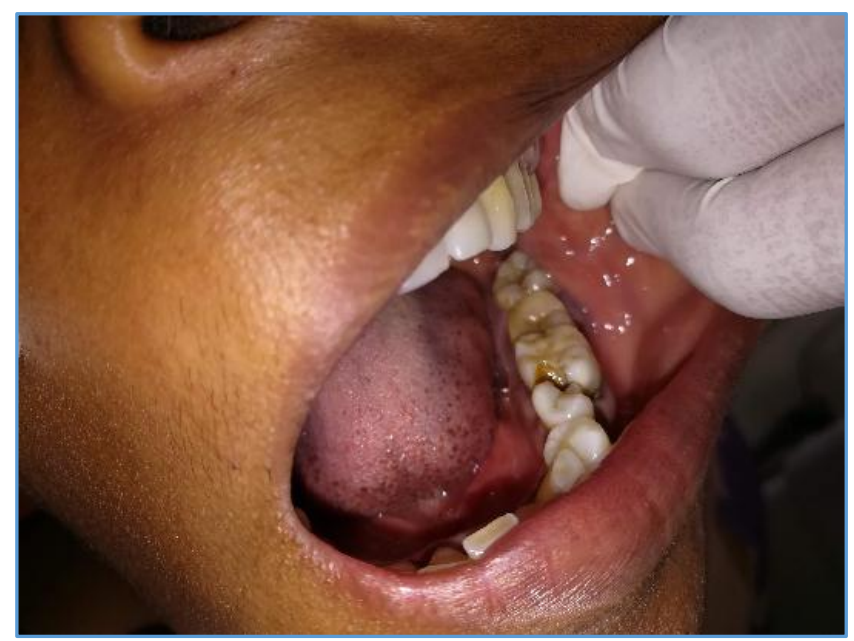

Figure 1. Pre-Op Picture

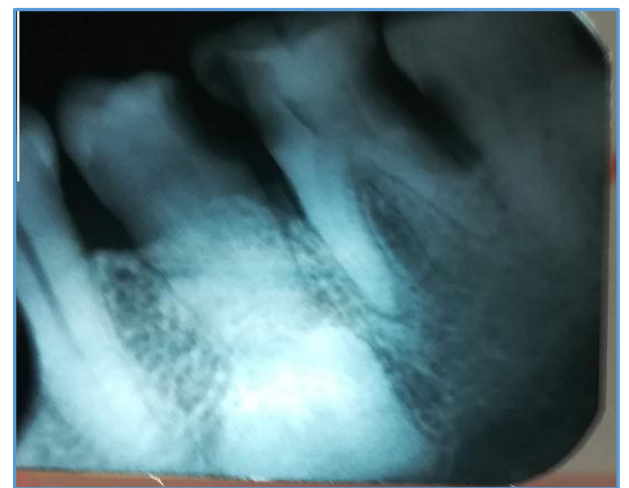

Figure 2. IOPA showing Periapical Radiopacity in relation to 34,35

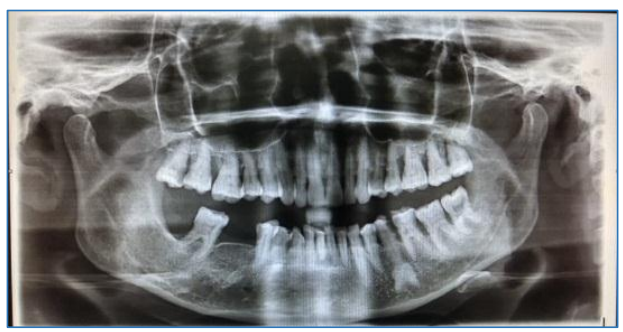

Figure 3. OPG showing well-defined Radiopaque Structure

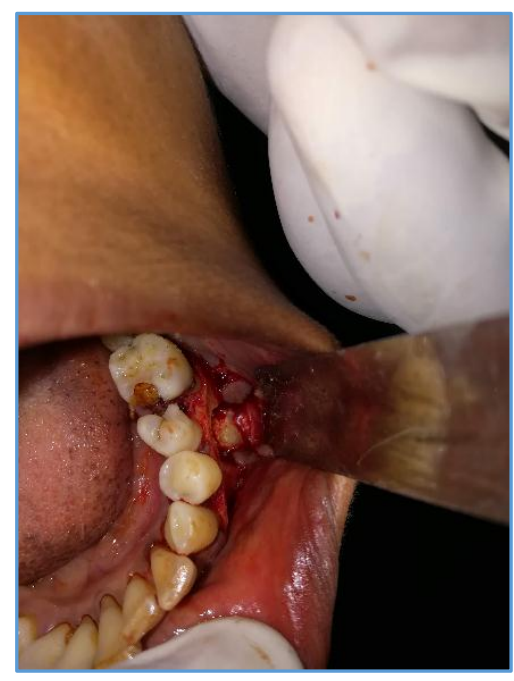

Figure 4. Surgical picture showing the Mass Structure

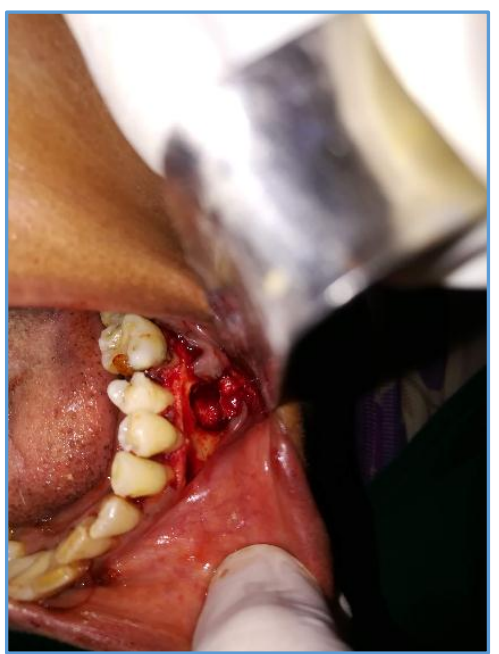

Figure 5. Surgical Site after extraction of the Mass Structure 


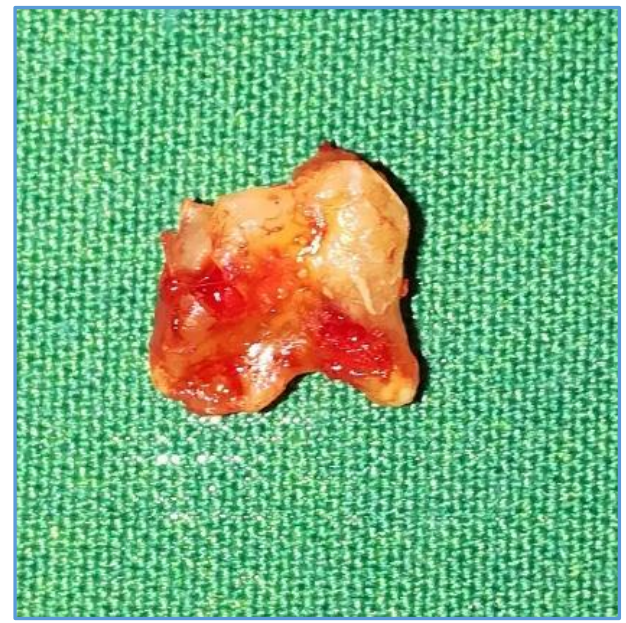

Figure 6. Excised Mass Structure

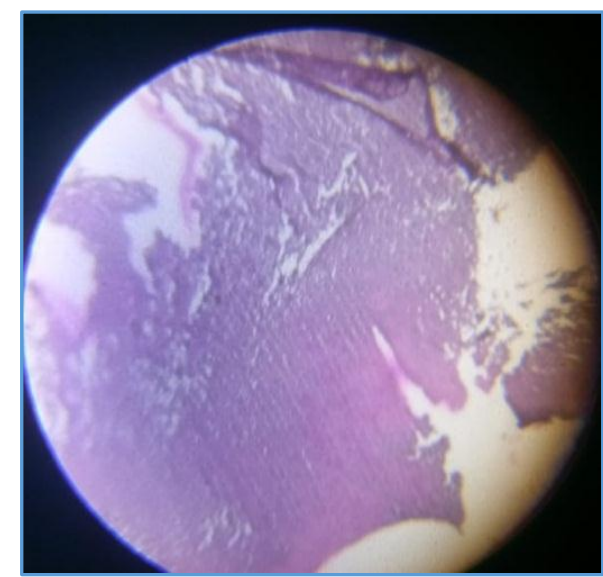

Figure 7. Histopath Picture

\section{REFERENCES}

[1] Reichart P, Philipsen HP. Odontogenic tumours and allied lesions. London: Quintessence Publishing 2004: p. 141-7.

[2] Batra P, Gupta S, Rajan K, et al. Odontomes-diagnosis and treatment: a 4 case report. J Pierre Fauchard Acad 2003;19:73-6.
[3] Bordini J Jr, Contar CM, Sarot JR, et al. Multiple compound odontomas in the jaw: case report and analysis of the literature. J Oral Maxillofac Surg 2008;66(12):2617-20.

[4] Shafer WG, Hine MK, Levy BM. Text book of Oral Pathology. $4^{\text {th }}$ edn. Philadelphia: WB Saunders Company 1993: p. 308-12.

[5] Neville BW, Damm DD, Allen CM, et al. Oral and maxillofacial pathology. Philadelphia: Saunders 1995: p. 531-3.

[6] Nagaraj K, Upadhyay M, Yadav S. Impacted maxillary central incisor, canine and second molar with 2 supernumerary Teeth and an odontoma. Am J Orthod Dentofac Orthop 2009;135(3):390-9.

[7] Vengal M, Arora H, Ghosh S, et al. Large erupting complex odontoma: a case report. J Can Dent Assoc 2007;73(2):169-73.

[8] Dua N, Kapila R, Trivedi A, et al. An unusual case of erupted composite complex odontoma. J Dent Sci Res 2011;2:1-5

[9] Serra-Serra G, Berini-Aytes L, Gay-Escoda C. Erupted odontomas: a report of three cases and review of literature. Med Oral Patol Oral Cir Bucal 2009;14(6):E299-303.

[10] Hitchin AD. The aetiology of the calcified composite odontomes. Br Dent J 1971;130(11):475-82.

[11] Tomizawa M, Otsuka Y, Noda T. Clinical observations of odontomas in Japanese children: 39 cases including one recurrent case. Int J Paediatr Dent 2005;15(1):3743.

[12] Philipsen HP, Reichart PA. Classification of odontogenic tumours. A historical review. J Oral Pathol Med 2006;35(9):525-9.

[13] Nelson BL, Thompson LDR. Compound odontoma. Head and Neck Pathol 2010;4(4):290-1.

[14] Diego JV, Pablo CG, Eduardo EC. Odontoma located within the inferior alveolar nerve: radiographic diagnosis and surgical management of a clinical case. Rev Esp Cir Oral Maxilofac 2009;31(4):264-9. 